\title{
REFLEXÃO SOBRE O CUIDADO COMO ESSÊNCIA DA LIDERANÇA EM ENFERMAGEM
}

\author{
Reflexion on the care as essence of nursing leadership. \\ Reflexión sobre el cuidado como idea principal del \\ liderazgo en enfermería.
}

Maria Grasiela Teixeira Barroso ${ }^{2}$

\section{RESUMO}

0 presente texto tem como objeto o cuidado como essência da liderança em enfermagem. 0 objetivo foi suscitar reflexão sobre o resgate do cuidado como essência da liderança em enfermagem. Trata-se de uma análise crítica-reflexiva realizada a partir da obra 0 monge e o executivo - uma história sobre a essência da liderança, de James C. Hunter. Como metodologia, foi usada a análise de conteúdo. A análise temática dos resultados aponta a relevância de repensar a liderança em enfermagem com base em um novo paradigma: a liderança para o cuidado pelo cuidado. Conclui-se que o cuidado necessita ser resgatado para a liderança em enfermagem.

Palavras-chave: Enfermagem. Liderança. Cuidados de Enfermagem

\begin{abstract}
The present text has as subject, the care as essence of nursing leadership. The objective was to arouse reflexion on the recovery of care as essence of nursing leadership. It is a critical and reflexive analysis carried out considering the book The Servant: A Simple Story about the True Essence of Leadership by James C. Hunter. As methodology, it was used the contents analysis. The thematic analysis of the results points to the relevance of rethink the nursing leadership based on the new paradigm: the leadership for the care by the care. It was conclude that the care needs to be recovered to nursing leadership.
\end{abstract}

\section{Resumen}

El presente texto tiene como objeto el cuidado como esencia del liderazgo en enfermería El objetivo fue producir reflexión a respecto del resgate del cuidado como esencia del liderazgo en enfermería. Se refiere a un análisis crítico-reflexivo realizado a partir de la obra El monje y el Ejecutivo - Una historia sobre la esencia del liderazgo, de James C. Hunter. Como metodología, fue usado el análisis del contenido. El análisis temático de los resultados apunta hacia la relevancia de pensar una vez más el liderazgo en enfermería con base en un nuevo paradigma: el liderazgo para el cuidado por el cuidado. Concluyese que el cuidado necesita ser resgatado para el liderazgo en enfermería. 


\section{INTRODUCÃO}

0 acelerado processo de desenvolvimento pelo qual alguns países vêm passando nas últimas décadas exige que profissionais das mais diversas áreas de atuação ingressem no mercado de trabalho com uma nova visão de mundo, na qual estejam presentes valores como competência, crescimento mútuo, atitude positiva, compromisso, honestidade e autodisciplina. Esses valores permeiam um dos termos mais discutidos na atualidade do universo profissional: a liderança.

Tema de inúmeros livros de autoajuda e direcionamento profissional, a liderança é uma habilidade que pode ser construída por profissionais que almejem uma posição de destaque no mercado de trabalho ${ }^{1}$. Pelos princípios de sua formação, a enfermeira tende a desenvolver, quase que de forma inevitável, habilidades de liderança, principalmente em virtude das tarefas que lhe são exigidas. É necessário que a enfermeira desempenhe, seja em instituições hospitalares ou em atividades de saúde comunitária, o papel de líder, uma vez que está diretamente envolvida com análise crítica, identificação de problemas, tomada de decisões, planejamento e implementação de cuidados, alocação de outros profissionais da equipe de enfermagem e motivação dos profissionais da equipe de saúde, por exemplo.

A atuação da enfermeira como líder é fato observado e analisado por profissionais de outras áreas que lidam com 0 fenômeno da liderança. James Hunter, em sua obra intitulada "O monge e o executivo - uma história sobre a essência da liderança"', ressalta a visão e atuação da enfermeira como líder, inclusive destacando-a como um profissional que possui habilidades de liderança por vezes superiores mesmo àqueles que teoricamente deveriam possuí-la como uma característica nata, como os executivos e outros profissionais que lidam diretamente com gerenciamento de produção.

$\mathrm{Na}$ obra supracitada, a evidência da enfermeira como líder consiste em sua postura fundamentada no cuidado, destoando de antigos paradigmas, os quais enfocavam a liderança como uma habilidade caracterizada pelo poder centralizador, no qual o relacionamento entre os membros da equipe acontece por meio de uma relação de poder, por parte do até então considerado líder, e subserviência por parte dos demais. No novo paradigma, o líder consiste naquela pessoa que, por meio do diálogo, motiva as pessoas a trabalhar com entusiasmo na busca dos objetivos determinados pela equipe, sendo que estes e o relacionamento interpessoal são considerados e igualmente valorizados por meio do cuidado, que transcende o âmbito assistencial e alcança o universo da liderança'.

Entendendo a necessidade emergente de divulgar novos paradigmas sobre liderança no universo dos sistemas de saúde, enfocando o papel da enfermeira como líder nas equipes onde atua, realizamos o presente estudo, com o objetivo de suscitar reflexão sobre o resgate do cuidado como essência da liderança em enfermagem.

\section{METODOLOGIA}

Este estudo consiste em uma descrição baseada na análise crítico-reflexiva da obra 0 monge e o executivo - uma história sobre a essência da liderança' ', de James C. Hunter, consultorchefe da J. D. Associados, uma empresa de trabalho e treinamento. James Hunter possui vasta experiência nas áreas de liderança funcional e organização de grupos comunitários. Já lançou alguns livros sobre liderança e frequentemente é solicitado para ministrar palestras e outros tipos de exposições sobre o tema. Na obra supracitada, apresenta a história de um grupo de pessoas que exercem papel de gerentes nas mais diversas áreas e que se recolhem em um retiro durante uma semana para aprender a desempenhar a liderança. Entre os personagens da história está Kim, uma enfermeira do centro neonatal que se destaca dos demais participantes do retiro por sua facilidade em decifrar as entrelinhas da liderança. Definida na narrativa como "a mais brilhante dos participantes", a enfermeira utiliza-se em vários trechos da obra de conceitos aprendidos em sua profissão e ajuda a explicar que a essência da liderança está em cuidar na expressão do servir, ou seja, identificar e satisfazer às necessidades da equipe a fim de proporcionar um ambiente de trabalho saudável, favorável ao cuidado de enfermagem. Os trechos da obra referentes às consideraç̃̃es da enfermeira sobre o tema liderança foram alvos deste estudo.

Para discussão sobre a obra retrocitada dentro de um contexto reflexivo, utilizamos o método de análise de conteúdo². Inicialmente, selecionamos textos relacionados com o objeto da pesquisa e realizamos a leitura flutuante, procurando absorver todo conteúdo sobre cuidado e liderança; posteriormente, procuramos nos conteúdos a exaustividade, a representatividade e a homogeneidade dos conceitos e pressupostos, que consistiu na constituição do corpus, a última fase foi caracterizada pelos resultados obtidos e interpretação, quando realizamos a interpretação da obra com base nos conceitos de outros autores que tratam dos temas: cuidado e liderança em enfermagem. Com suporte na análise de conteúdo, emergiram dois temas: "0 cuidado e a liderança em enfermagem: compreendendo esta inter-relação" e " 0 cuidado como essência da liderança para o cuidado: resgatando fundamentos de enfermagem". 0 primeiro tema ressalta a interrelação do cuidado de enfermagem e da liderança em enfermagem. No segundo, tecemos maiores considerações sobre o resgate do cuidado como essência da liderança em enfermagem.

\section{0 cuidado e a liderança em enfermagem: compreendendo esta inter-relação.}

0 cuidar é a essência da Enfermagem, constituindo pilar profissional e foco central das ações gerenciais e assistenciais dos enfermeiros ${ }^{3,4}$. Com base na importância do cuidar na profissão de enfermagem, estruturam-se as discussões sobre 0 cuidado e suas dimensões, as quais, de certa forma, abrem espaço para a visibilidade da enfermeira como líder na prática do cuidar ${ }^{5}$. 
Entretanto, a realidade da valorização da enfermeira como líder por intermédio de sua postura vinculada ao cuidado ainda está em processo de desenvolvimento e aprimoramento. 0 modelo administrativo que predominou até o final do século XX fundamentava-se na prescrição e normatização de tarefas para o cuidado, as quais eram estritamente racionais e quase isentas de aproximação empática com o outro, seja esse outro o cliente ou um membro da equipe de enfermagem 6 .

0 modelo administrativo de enfermagem referido mantevese vinculado à definição de cuidado, que, por sua vez, teve durante muito tempo sua conceituação restrita ao simples ato de prestar assistência. A enfermeira era definida como aquela que socorria, auxiliava o ser cuidado. Nesse sentido, o cuidado se limitava a uma ação centrada na tarefa. A relação interpessoal entre cuidador e ser cuidado não era considerada. 0 ato de cuidar era caracterizado como uma relação distante entre a enfermeira, a parte ativa, e o cliente, a parte passiva, sendo este totalmente dependente daquele. Algumas enfermeiras ainda possuem essa visão limitada e limitante sobre o cuidado, considerando-o um ato caracterizado apenas pela implementação de técnicas sistematizadas, baseadas em padrões predeterminados, que desconsideram a necessidade do outro nas ações assistenciais e de liderança em enfermagem?

0 cuidado autêntico vai além da assistência à doença, assiste ao indivíduo em várias dimensões e, o que é mais importante, ajuda o cliente a cuidar de seu próprio $\operatorname{ser}^{8}$. 0 poder não é utilizado como instrumento no cuidado autêntico, pois, por meio do poder, a enfermeira estabelece uma relação prejudicial com o outro ${ }^{1}$. No contexto de uma visão ampliada sobre o cuidado, deve-se entender o cuidar além de uma visão epistemológica, no intuito de promover um cuidado holístico, diferenciado e fundamentado na relação interpessoal entre profissionais e clientes, e profissionais entre $i^{6}$. Kim lembra que os profissionais da saúde são responsáveis pela manutenção de condições favoráveis ao desenvolvimento dos seres humanos ${ }^{1}$. Assim como nas ações assistenciais, as condições favoráveis ao cuidado são proporcionadas não apenas por meio de administração de medicamentos, realização de curativos ou cirurgias, por exemplo, mas, sobretudo, por meio de relacionamentos baseados no respeito, na empatia, na aceitação, no compromisso e no amor, que se iniciam na liderança dos membros da equipe de enfermagem.

0 cuidado de enfermagem possui um sentido único e transcendental, pois consiste em promover as pessoas a um estado em que percebam o sentido e a importância de cuidar de si, assim como se compreendam como um ser-no-mundocom-o-outro e, portanto, considerem suas responsabilidades consigo e com o próximo 4 .

No contexto transcendental, o saber cuidar implica desenvolver sentimentos éticos com o ser humano e com o meio onde se está inserido ${ }^{4}$. Dessa forma, ser enfermeira não consiste apenas em prestar cuidados ao cliente, mas, também, cuidar da relação empática com este, do ambiente físico, das relações com outros membros da equipe de saúde e com os membros da equipe de enfermagem. Sob esta perspectiva, vislumbram-se a qualidade de vida dos envolvidos e o constante movimento em busca da realização existencial ${ }^{4}$.

0 cuidado de enfermagem não deve ser separado do relacionamento empático com o outro e com o mundo, uma vez que está inter-relacionado com a comunicação entre o enfermeiro e o cliente, entre a enfermeira e 0 ambiente, e entre as enfermeiras e a equipe de enfermagem ${ }^{5}$. Kim explica que quando um líder se concentra apenas na tarefa, subestimando 0 relacionamento entre os membros da equipe, gera descontentamento e falta de motivação no grupo, o qual passa a apresentar constantes saídas de profissionais da equipe ${ }^{1}$. Essa rotatividade, além de refletir a não aceitação da enfermeira como líder, prejudica a assistência ao cliente, já que interfere negativamente no ambiente de cuidado, na qualidade do trabalho e na confiança nos profissionais.

A essência da enfermeira está no cuidado, seja com o outro ou com a gerência de quem cuida do outro, a equipe de enfermagem. A liderança para o cuidado tende a se desenvolver de forma quase inevitável como habilidade da enfermeira. Nas relações de enfermagem, a enfermeira, líder da equipe, funciona como inspiração para os demais membros, que tendem a seguir seus exemplos ${ }^{9}$. Por meio de sua conduta profissional peculiar, que tem o cuidado como essência de sua formação, é convidada a intermediar as relações e difundir a valorização do cuidado dentro da equipe de saúde, sabendo ouvir, estando disponível, demonstrando responsabilidade e boa comunicação ${ }^{5}$.

0 cuidado, portanto, consiste em atitude que emerge do desejo de estruturar-se para conhecer o outro em sua totalidade $\mathrm{e}$, consequentemente, conhecer a si mesmo ${ }^{4}$. Para isso, 0 exercício do cuidar deve envolver uma frequente avaliação pessoal, não só para que a enfermeira esteja disposta a utilizar seu conhecimento técnico-científico para o cuidado, mas, sobretudo, para que o cuidado seja exercido por meio de uma relação de sensibilidade e compromisso com o outro ${ }^{3}$. Este sentimento é definido por Kim como uma presença total junto ao outro, isto é, uma presença não somente física, mas emocional e mental, um real interesse em conhecer o outro, identificar seus sentimentos e auxiliá-lo a satisfazer suas necessidades dentro do contexto no qual está inserido ${ }^{1}$. A respeito desta definição, compreendemos que se comprometer envolve empatia, que vai além da atitude física de estar junto, uma vez que exige que a enfermeira se coloque no lugar do outro a fim de sentir seus anseios, necessidades, ou até mesmo para tencionar compreender qual a visão que 0 outro possui sobre 0 comportamento da própria enfermeira.

Com a evolução dos conceitos de saúde e cuidado, que passaram a adquirir definições amplas, fundamentadas principalmente no holismo e na verdadeira aproximação com o outro e com o mundo, o modelo administrativo e, consequentemente, de liderança em enfermagem, passou a ser questionado e analisado segundo paradigmas diferenciais de 
efetivação de práticas, tanto assistenciais como gerenciais ${ }^{6}$. Kim comenta que, de acordo com as experiências e ensinamentos que tivemos, incorporamos paradigmas que nem sempre são corretos e estamos transferindo-os para uma realidade em que eles são inadequados ${ }^{1}$. Portanto, 0 questionamento de paradigmas é necessário para que não haja o risco de ficarmos na inércia em um mundo em constante processo evolutivo.

A partir da revisão de paradigmas sobre liderança em enfermagem, questionamentos no âmbito assistencial podem ser transformados em qualidade no âmbito interprofissional ${ }^{9}$. Dentro deste contexto, verifica-se a importância do resgate do conceito de cuidado para o novo conceito de liderança para o cuidado. A enfermagem desperta para as várias formas de cuidar, assistencial e gerencial, sendo que ambas são entendidas e valorizadas como ferramentas para um fim comum - a promoção do cuidado do cliente - e são realizadas a partir da liderançą ${ }^{10}$.

Em interface a este emergente paradigma sobre a liderança em enfermagem, observa-se ainda a dificuldade no relacionamento entre os profissionais da equipe de enfermagem. Estudos evidenciam entraves no trabalho em equipe e a falta de habilidade de liderança ${ }^{11}$. A falta de sintonia entre os profissionais da equipe, além de prejudicar a assistência, proporciona um ambiente de trabalho desagradável e com pouca produtividade. Isso pode se refletir de forma negativa na saúde dos clientes, pois, como Kim explica, por mais que possamos manter um relacionamento saudável com os clientes, estes provavelmente manterão um contato mais próximo com as pessoas que lideramos ${ }^{1}$.

A liderança é uma função gerencial da enfermeira e depende do seu exercício efetivo ${ }^{10}$. Constituindo este exercício está a habilidade em cuidar daqueles que ela lidera, motivando-os e convencendo-os a trabalhar para o bem comum da equipe, que é o cuidado de si e do cliente. Nesse sentido, a cordialidade, a empatia e o convívio são elementos que permeiam 0 cumprimento da tarefa de enfermagem e a manutenção de relacionamentos saudáveis na equipe, pois estreitam relações entre os seres humanos e fundamentam 0 ato de cuidar ${ }^{1,4}$.

\section{O cuidado como essência da liderança para o cuidado: resgatando fundamentos de enfermagem}

A figura do líder prevalente no subconsciente de algumas enfermeiras ainda é caracterizada como aquela pessoa que, por meio do poder, consegue que um grupo execute as tarefas que lhes são impostas. Em suma, o "líder", neste contexto, dita regras que são seguidas para que se escape das tão temidas punições. Esse modelo de liderança, baseado no poder e nas punições, até algum tempo foi eleito como eficiente, pelo menos em curto prazo. Entretanto, em longo prazo, os profissionais apresentam-se descontentes e sem entusiasmo com o trabalho ${ }^{1}$.

Quando uma enfermeira exerce liderança por meio do poder, embora as tarefas sejam cumpridas, os relacionamentos entre os membros da equipe são bastante prejudicados. Através do poder, podemos fazer com que as pessoas cumpram suas tarefas, mas com o passar dos tempos os relacionamentos são corroídos $^{12,1}$. Kim explica que a liderança pelo poder não resiste por muito tempo, pois o ambiente de trabalho tornar-se-á hostil e prejudicial aos relacionamentos e, consequentemente, aos resultados do trabalho da equipe ${ }^{1}$. De fato, em uma equipe onde os relacionamentos não estão for talecidos pelo laço de compromisso, cumplicidade e respeito, a figura do líder não é reconhecida e, consequentemente, o grupo desvia o foco do objetivo comum e acaba por perder a motivação para cumprir tarefas exigidas. Mas se liderar significa a capacidade de conseguir que as coisas sejam feitas através das pessoas, e ao trabalhar com pessoas sempre haverá duas dinâmicas em jogo - a tarefa e o relacionamento, sendo este prejudicado pelo poder - como conseguir liderar se não for por meio do poder?

Outra forma de conseguir exercer liderança é pela autoridade. Diferente do poder, que é a faculdade de se utilizar de posição ou força para coagir alguém em posição inferior a realizar uma tarefa, mesmo sem vontade ou motivação, a autoridade consiste em motivar as pessoas a fazerem, de boa vontade, o que o líder quer por causa da imagem positiva e da influência pessoal deste 1 . Os principais líderes que já existiram utilizaram-se justamente da autoridade para influenciar milhares de pessoas e se fazerem inesquecíveis por grande parte da humanidade. 0 maior exemplo de liderança, Jesus de Nazaré, desafiou grandes figuras políticas de sua época, demonstrando que o poder destes não superaria a autoridade construída pelos princípios de amor, humildade, diálogo e união. A autoridade de Jesus de Nazaré até hoje se mantém influenciando datas comemorativas, o calendário e 0 comportamento de muitas pessoas. No contexto atual, observa-se que a abordagem sobre líderes e equipes efetivas contempla os princípios de uma relação dialógica, de compartilhamento, e não de supremacia e poder ${ }^{13,14}$. A tendência de enfatizar a relação bilateral entre o líder e os demais membros da equipe, de forma que o primeiro intervenha para que todos se sintam igualmente importantes e participem do processo, fornece indícios de que a liderança pela autoridade parece ser mais sólida e eficiente do que a liderança pelo poder.

Todavia, a autoridade não é um atributo facilmente adquirido. Para alcançar o status de pessoa com autoridade sobre os demais, é necessário que se apresente uma série de características peculiares que contribuem para que o líder seja percebido como alguém que se destaca entre os demais. Kim cita 10 qualidades de um líder com autoridade: honestidade, comportamento exemplar, cuidado, compromisso, interesse na escuta, confiabilidade, respeito, motivação, atitude positiva e entusiástica, e empatia. A enfermeira explica que nenhuma destas qualidades é nata, pois consistem em atributos que mais se assemelham ao comportamento, que é escolha e, consequentemente, pode ser ou não adquirido conforme 0 interesse e a vontade 1 . Entre as qualidades supracitadas, merece destaque o cuidado, que, como os outros atributos, 
exige que o líder possua real interesse em desenvolvê-lo nas relações que estabelece com seus liderados, principalmente tendo o cuidado como foco e objetivo da equipe de enfermagem.

Entretanto, o interesse e a vontade de adquirir autoridade podem não existir em virtude de antigos paradigmas sobre a liderança, os quais impedem de forma inconsciente a aceitação do novo. Isso acontece porque, ao estabelecer os primeiros contatos com o universo da liderança por meio de líderes que se utilizaram do poder, a pessoa armazena a informação de que toda liderança é exercida pelo poder.

Em uma representação cognitiva, a administração característica de um modelo de liderança baseado no poder pode ser caracterizada por uma pirâmide que parte de uma base formada pelos empregados e segue para o chefe. Kim afirma que, nesse tipo de organização, os propósitos da equipe de enfermagem perdem o sentido, uma vez que o foco é o chefe (a enfermeira), e não o cuidado ao cliente. A liderança, nesse modelo, se inicia no líder e tem o mesmo como fim, tratando-se, portanto, de uma liderança sem propósitos ${ }^{1}$. 0 modelo de liderança pelo poder ainda mantém-se presente em algumas equipes de saúde no contexto atual, condicionando enfermeiras a supervalorizar a tarefa em detrimento do relacionamento com os membros da equipe, o que acaba prejudicando a própria tarefa de cuidar do cliente.

Na liderança em enfermagem, é necessário que o resgate do cuidado seja uma constante, visto que ele é o foco central da profissão, fundamentando-a e justificando as ações da equipe de enfermagem. Entretanto, para que o cuidado seja elemento presente nas ações de enfermagem, é preciso que ele esteja inserido inicialmente nas relações entre os próprios profissionais, a fim de que não haja empecilhos para os processos assistenciais. A enfermeira deve desenvolver constantemente pensamento crítico e manter acesas em sua atuação como líder as motivações do cuidador e a empatia ${ }^{1,15}$. Em uma situação de liderança comentada por Kim, o dever de um líder de enfermagem é resolver entraves a fim de que os profissionais da equipe de enfermagem possam servir a seus clientes. De acordo com seu raciocínio, a remoção de obstáculos dentro da própria equipe de enfermagem consistiria em uma forma de servir ao cliente'.

No sentido supracitado, servir refere-se a satisfazer às necessidades também da equipe para que esta permaneça psicologicamente preparada para realizar o cuidado. Como enfermeira, a personagem descrita no livro reflete sobre a liderança a partir de um novo paradigma: o cuidado. A transcendência da liderança pelo poder para a liderança pela autoridade, segundo o referencial analisado, deve ser realizada necessariamente por meio do servir, isto é, do cuidado, citado anteriormente na lista de qualidades de um líder, definida por $\mathrm{Kim}^{1}$. Cuidamos de nós, daqueles que lideramos e do ambiente para que o paciente receba um cuidado autêntico.
Em relação a este novo paradigma, a enfermagem parece possuir certa familiaridade, uma vez que a profissão utiliza-se da Teoria das Necessidades Humanas Básicas, de Abraham Maslow. A teoria é baseada na premissa de que os seres humanos possuem cinco níveis hierárquicos de necessidades que são em ordem crescente: comida e água; moradia, segurança e proteção; pertencimento e amor; autoestima; $e$ autorrealização. Kim transportou esses níveis para a realidade da liderança em enfermagem e obteve o raciocínio de que benefícios e um ambiente de trabalho seguro e agradável satisfariam às necessidades do primeiro e segundo níveis, respectivamente. Assim, os sentimentos de pertencer à instituição e de ser amado consistiriam em necessidades motivadoras. Quando um membro da equipe estabelece relaç̃̃es saudáveis dentro de um ambiente acolhedor, satisfaz suas necessidades de autoestima, o que, por sua vez, o encoraja a desenvolver uma assistência de qualidade, tendo seu trabalho encorajado, apreciado e reconhecido ${ }^{1}$. A idéia expressa por Kim vai ao encontro não só dos princípios administrativos, mas, sobretudo, dos princípios filosóficos da enfermagem, haja vista que a profissão tem o cuidar como alicerce e este exige compromisso com o outro, o que, por sua vez, evolve a empatia e a identificação das necessidades do outro. No contexto do conteúdo analisado, o outro é aquele a quem a enfermeira se dirige durante suas ações de enfermagem, assistenciais ou de liderança. Dessa forma, identificar e satisfazer às necessidades dos membros da equipe, com vistas à motivação do grupo, consiste em um princípio de liderança em enfermagem.

No contexto da teoria supracitada e da analogia feita por Kim, a finalidade do processo, a autorrealização, nada mais é do que fazer com que as pessoas se tornem o melhor que possam ser ${ }^{1}$. Eé exatamente aí que se encontra a congruência entre cuidado e liderança, pois, resgatando o que foi anteriormente dito, o cuidado vai além de uma visão epistemológica, consiste em promover as pessoas ao seu mais alto nível de bem-estar. 0 líder deve proporcionar condições para que as pessoas possam transcender. Por meio do cuidado, do serviço, o líder estabelece uma relação dialógica e interativa, promove autorreflexão nos membros de sua equipe e os encaminha ao pensamento crítico que, por si só, consiste em um meio para o crescimento pessoal e profissional ${ }^{1}$.

Cuidar daqueles que lideramos, liderar por meio do servir, parece um paradoxo. Como exercer essa forma de liderança em meio a tantas obrigações, metas e solicitações? Isso é uma habilidade que exige empatia, saber estar-com-o-outro, o que, por conseguinte, exige comprometimento e amor. Este é definido por Kim como o ato de servir ao outro através da identificação de suas reais necessidades ${ }^{1}$. É importante, diante desse raciocínio, fazer uma ressalva, pois, servir, no contexto da liderança, não significa satisfazer a vontade dos membros da equipe, mas sim identificar as necessidades para que eles se desenvolvam e se autorrealizem dentro da equipe. A enfermeira líder deve possuir, para tanto, discernimento sobre 
liderança pelo poder, liderança pela autoridade e, principalmente, a importância de servir aos membros da equipe no sentido de identificar necessidades que estejam direta ou indiretamente relacionadas à motivação para o trabalho.

A liderança em enfermagem, construída a partir de um novo paradigma, seria desenvolvida sobre a autoridade ou influência (e não sobre o poder), que por sua vez seria baseada no serviço e no cuidado, que são construídos pelo amor-doação. Isso cria um ambiente favorável ao cuidado assistencial. 0 líder é responsável pela manutenção de um ambiente saudável por meio de relações harmoniosas entre os membros da equipe, 0 que, consequentemente, se refletirá na saúde dos pacientes. $A$ liderança para o cuidado é, portanto, baseada na liderança pelo cuidado. A respeito disso, Kim comenta que, quando cuidamos, servimos e nos sacrificamos pelo outro. Desse modo, exercemos influência, autoridade sobre o outro, que passa a

\section{CONSIDERAÇÕES FINAIS}

Assim como o conceito de cuidado tem sido objeto de reflexão, adquirindo definições amplas que envolvem, sobretudo, uma visão para além da epistemologia, a liderança em enfermagem também deve atender às exigências de um mundo em constante processo de desenvolvimento. Para isso, é necessário que antigos paradigmas sejam frequentemente analisados a partir de um olhar sobre a realidade atual da enfermagem.

Se a enfermagem defende que o cuidado seja a sua essência, seus valores devem orientar a liderança. Entretanto, a liderança em enfermagem ainda parece ser vista por alguns profissionais como uma função independente, desprendida do foco da enfermagem: o cuidado. Em meio a conceitos antigos sobre 0 papel de um líder, baseado na liderança pelo poder, a enfermeira muitas vezes abandona o conceito autêntico de cuidar durante a tarefa de liderar.

A desconsideração do conceito de cuidar durante o processo de liderança para o cuidado pode proporcionar um ambiente de trabalho desfavorável à assistência ao cliente. Com suporte

\section{REFERÊNCIAS}

1.Hunter JC. 0 monge e o executivo: uma história sobre a essência da liderança. Rio de Janeiro (RJ): Sextante; 2004.

2.Minayo MCS. 0 desafio do conhecimento: pesquisa qualitativa em saúde. São Paulo (SP): Hucitec; 2006.

3.Ravelli APX, Motta MGC. 0 lúdico e o desenvolvimento infantil: um enfoque na música e no cuidado de enfermagem. Rev Bras Enferm 2005 set/out; 58 (5):611-13.

4.Silva LWS, Francione FF, Sena ELS, Carraro TE, Randünz V. 0 cuidado na perspectiva de Leonardo Boff, uma personalidade a ser (re)descoberta na enfermagem. Rev Bras Enferm 2005 jul/ago; 58(4): 471-75.

5.Castanha ML, Zagonel IPS. A prática de cuidar do ser humano sob o olhar da equipe de saúde. Rev Bras Enferm 2005 set/out; 58(5): 556-62. nos considerar líder ${ }^{1}$. Em consonância com o raciocínio expresso no comentário da personagem Kim, compreendemos que a enfermeira só poderá exercer autoridade como líder se os membros da equipe a reconhecerem como tal. Em outras palavras, a liderança é uma função que deve ser conquistada, e essa conquista se inicia no relacionamento empático com os membros da equipe. Estes, percebendo que a enfermeira possui interesse verdadeiro em suas necessidades, e não apenas no cumprimento de tarefas, atribuirão autoridade e reconhecerão sua liderança.

0 líder pode influenciar escolhas através da comunicação e, assim, promover os liderados a serem o melhor que possam ser. Mas, antes disso, é necessário que o próprio líder faça suas escolhas no processo de liderar. É preciso que ele dê o primeiro passo. É preciso que ele esteja disposto a servir por meio do cuidado com aqueles que ele lidera ${ }^{1}$.

nos achados, percebemos que, assim como a assistência, a liderança, que também consiste em uma ação da enfermeira, deve fundamentar-se no alicerce da profissão, o cuidado.

No contexto atual da enfermagem, sustentamos a idéia de que só é possível exercer a liderança para o cuidado pelo próprio cuidado com os membros da equipe que a enfermeira lidera. Como ressaltado na obra-alvo desta reflexão, acreditamos que a enfermeira possui subsídios para desenvolver uma liderança de sucesso, visto que possui os princípios da essência da liderança enraizados em sua filosofia profissional. Entretanto, é preciso que estes princípios sejam resgatados à luz de um novo paradigma, não mais baseado na liderança pelo poder.

Espera-se que este estudo contribua para a reflexão sobre o resgate do cuidado para uma das mais importantes e atuais funções da enfermeira: a liderança. A partir do paradigma de uma liderança pelo cuidado, poderão ser obtidos avanços significativos no ambiente de cuidado, nas relações entre os profissionais da equipe de enfermagem e no relacionamento entre profissionais e clientes.

6.Kurcgant $\mathrm{P}$, Ciampone MHT. A pesquisa na área de gerenciamento em enfermagem no Brasil. Rev Bras Enferm 2005 mar/abr; 58(2): 161-64.

7.Ferraz F, Silva LWS, Silva LAA, Reibnitz KS, Backes VMS. Cuidar educando em enfermagem: passaporte para 0 aprender/educar/ cuidar em saúde. Rev Bras Enferm 2005 set/out; 58(5): 607-10.

8.Waldow VR. 0 cuidado na saúde: as relações entre o eu, o outro e 0 cosmo. Petrópolis (RJ): Vozes; 2004.

9.Balsanelli AP, Cunha ICKD. Liderança no contexto da enfermagem. Rev Esc Enferm USP 2006; 40(1): 117-22.

10Christovam B, Santos I. Instituição da liderança do enfermeiro em questões de saúde. Rev Bras Enferm 2005 set/out; 58(5): 551-55. 
11 Abreu LO, Munari DB, Queiroz ALB, Fernandes CNS. 0 trabalho de equipe de enfermagem: revisão sistemática de literatura. Rev Bras Enferm 2005 mar/abr; 58(2): 2003-07.

12.Nóbrega-Therrien SM. A enfermeira e o exercício do poder na profissão: a trama da ambigüidade. Acta Paul Enf 2004; 17(1): 7986.
13.Rodrigues J, Zagonel IPS, Mantovani MF. Alternativas para a prática docente no ensino superior de enfermagem. Escola Anna Nery Rev Enferm 2007 jun; 11 (2): 313-17.

14.Freire P. Ação cultural para a liberdade e outros escritores. São Paulo (SP): Paz e Terra; 2002.

15 - Waldow VR. Estratégias de ensino na enfermagem: enfoque no cuidado e no pensamento crítico. Petrópolis (RJ): Vozes; 2005. 